International Journal of Automotive and Mechanical Engineering (IJAME)

ISSN: 2229-8649 (Print); ISSN: 2180-1606 (Online); Volume 8, pp. 1430-1441, July-December 2013

OUniversiti Malaysia Pahang

DOI: http://dx.doi.org/10.15282/ijame.8.2013.30.0118

\title{
EFFECT OF AGING TREATMENT ON THE MICROSTRUCTURES AND HARDNESS OF Fe-Ni-Cr SUPERALLOY
}

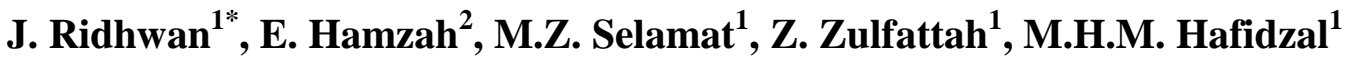 \\ ${ }^{1}$ Faculty of Mechanical Engineering, \\ Universiti Teknikal Malaysia Melaka \\ Hang Tuah Jaya, 76100 Durian Tunggal, Melaka \\ *E-mail: ridhwan@utem.edu.my \\ ${ }^{2}$ Faculty of Mechanical Engineering, Universiti Teknologi Malaysia, \\ 81310 UTM Skudai, Johor Bahru
}

\begin{abstract}
Aging treatment was conducted on $\mathrm{Fe}-\mathrm{Ni}-\mathrm{Cr}$ superalloy to observe its effect on the microstructures and hardness of the material. Solution treatments were carried out at $900^{\circ} \mathrm{C}, 975^{\circ} \mathrm{C}, 1050^{\circ} \mathrm{C}$, and $1125^{\circ} \mathrm{C}$ followed by water quenching. The samples were further treated with a double aging treatment at $720^{\circ} \mathrm{C}$ and $650^{\circ} \mathrm{C}$ for 4 hours and 12 hours respectively. Materials characterization techniques such as SEM, XRD, and optical microscopy were used to analyze the heat-treated samples. The $\mathrm{Fe}-\mathrm{Ni}-\mathrm{Cr}$ superalloy formed mainly a dendritic austenitic structure with $\mathrm{Cr}_{23} \mathrm{C}_{6}$ precipitated along the grain boundaries. Increase in solution treatment temperature results in dissolution of chromium carbide, coarser grain, and lower hardness for non-aged samples. Double aging treatment produced more chromium carbide, higher hardness, but no apparent change in grain size. Neither quenching nor aging treatments caused any phase transformation. The highest hardness value of $220.4 \mathrm{Hv}$ was recorded for the sample solution treated at $1125^{\circ} \mathrm{C}$ for 2 hours and water quenched, followed by 2 -step aging at temperature $720^{\circ} \mathrm{C}$ and $650^{\circ} \mathrm{C}$ for 4 hours and 12 hours respectively, and air cooled.
\end{abstract}

Keywords: Fe-Ni-Cr superalloy; solution treatment; aging; precipitation.

\section{INTRODUCTION}

Heat resistant material is one type of superalloy that is extensively used in engineering design especially in high temperature applications. The high temperature strength of all superalloys is based on the principle of a stable face-centered cubic (FCC) matrix combined with either precipitation or strengthening and solid-solution strengthening (ASM Handbook, 1991). Iron-nickel-chromium (Fe-Ni-Cr) alloy is one type of superalloy which is being used as heat resistant material. The combination of iron, nickel, and chromium provides the characteristics needed for this material to operate in a high temperature environment. Aging treatment prior to solution treating is one of the most common treatments used for superalloys (Moniruzzaman, Rakib, \& Matin, 2012). Usually solution treating will be the first step in the heat treatment process. The temperature for solution treating depends on the desired properties. Higher solutiontreating temperatures will result in some grain growth and more extensive dissolving of carbides. Lower solution-treating temperatures dissolve only a small amount of carbide and without grain growth (ASM Handbook, 1991). After solution treating, the material will usually undergo quenching. The purpose of this quenching is to maintain, at room temperature, the supersaturated solid solution obtained during solution treating. 
Quenching permits a finer age-hardening precipitate size. Cooling methods commonly used include oil and water quenching as well as various forms of air or inert gas cooling (ASM Handbook, 1991). The temperature for solution treating and the type of quenching medium depends on the property desired on the metal via the treatment process. Rapid cooling will decrease the diffusion rate while slow cooling will increase the diffusion rate of the material, which will result in different types of microstructure according to the present phase in the structure. Prior to quenching, the dissolve carbides will be in a metastable state where aging treatment is conducted to promote homogeneous carbide precipitation in matrix as the hardening phase. After aging, the resulting microstructure consists of large grains that contain the aging phases and a heavy concentration of carbides in the grain boundaries.

\section{HEAT TREATMENT}

In order to study the effects of aging treatment on the microstructure and hardness of Fe-Ni-Cr superalloy, the types of heat treatments selected were solution treating followed by aging. Table 1 shows the temperature and time for the respective heat treatment. Four samples underwent solution treating followed by double aging while another four underwent solution treatment (water quenched) only in order to serve as controlled samples.

Table 1. Double aging treatment.

\begin{tabular}{|c|c|c|}
\hline $\begin{array}{l}\text { Solution treating } \\
\text { temperature }\left({ }^{\circ} \mathrm{C}\right) \\
\text { for } 2 \mathrm{~h} \\
\text { (water quench) }\end{array}$ & $\begin{array}{l}\text { Reheating } \\
\text { temperature }\left({ }^{\circ} \mathrm{C}\right) \\
\text { for } 4 \text { hour } \\
\text { (air cool) }\end{array}$ & $\begin{array}{l}\text { Aging } \\
\text { temperature } \\
\text { for } 12 \mathrm{~h} \\
\text { (air cool) }\end{array}$ \\
\hline 900 & 720 & 650 \\
\hline 975 & 720 & 650 \\
\hline 1050 & 720 & 650 \\
\hline 1125 & 720 & 650 \\
\hline
\end{tabular}

All samples prepared for heat treatment were cut into $10 \times 10 \times 10 \mathrm{~mm}$ dimensions. The cutting process was conducted using an abrasive cutter with a continuous supply of coolant in order to avoid microstructure change from excessive heat. The heat-treated samples were analyzed by several materials characterization techniques: optical microscopy, scanning electron microscopy (SEM), energy dispersive $\mathrm{x}$-ray spectroscopy (EDX), x-ray diffraction (XRD), volume fraction analysis and a hardness test. As for metallurgical investigation, the specimen was mounted using a hot mounting process. The mounted specimen then underwent a surface finishing process before being inspected under an image analyzer and SEM. The surface finishing process included grinding by using abrasive silicon carbide paper with an increasing number sequence, started from 240, 320, 400, 600, 800, 1200, and 2400. Once grinding was completed, where only a soft scratch was detected on the surface, the specimen underwent a polishing process with alumina solution in order to produce a deformationfree surface which was flat, scratch-free, and had a mirror appearance. Finally, etchant was applied to the specimen surface to reveal the microstructure of the specimen. The etchant used was a combination of $45 \mathrm{ml}$ glycerol, $30 \mathrm{ml}$ hydrochloric acid, and $15 \mathrm{ml}$ nitric acid. 
A hardness test was conducted using a Vickers Hardness machine on the specimen before and after the heat treatment process. The load used was $30 \mathrm{kgf}$ and indentation duration was 15 seconds. In order to obtain an accurate and reliable result, five indentations were made in each specimen and the average reading was taken. Grain size is the diameter of individual grains on the microstructure of the material. However, Fe-Ni-Cr superalloy has a dendritic structure, so the grain size was measured according to dendritic arm spacing (DAS). Technically, the measurement is conducted perpendicularly along the dendrite and DAS is calculated by dividing the total length by the number of dendrites intercepted. The average value was calculated from 15 measurements on different dendrites. The volume fraction of the carbide was measured using image analyzer software, Omnimet. SEM micrographs were analyzed by measuring the area fraction of carbide on the microstructure. The area fraction is the fraction of the carbide area with respect to the matrix area. According to ASTM E124503, the relationship between the volume fraction and area fraction is as follows:

$$
V_{V}=A_{A}=\frac{A_{i}}{A_{T}}
$$

where

$\mathrm{V}_{\mathrm{V}}=$ the volume fraction

$A_{A}=$ the area fraction of the inclusion or constituent

$\mathrm{A}_{\mathrm{i}}=$ the area of the detected feature

$\mathrm{A}_{\mathrm{T}}=$ the measurement area (field area)

\section{RESULTS AND DISCUSSION}

\section{Microstructure Investigation}

Optical micrographs of water quenched and aged samples show that the microstructure retains an austenitic dendritic structure prior to heat treatment. However, grain coarsening was observed as the solution treatment temperature increased. Figures 1 and 2 show the optical micrographs of water quenched and aged samples. As shown in Figure 1, the austenitic dendritic structure was observed on water quenched samples as the solution temperature increased from $900^{\circ} \mathrm{C}$ to $1125^{\circ} \mathrm{C}$. In terms of dendritic size, a slight increase of dendritic arm spacing was observed as the temperature increased from $900^{\circ} \mathrm{C}$ to $1125^{\circ} \mathrm{C}$. Meanwhile, the aged samples shown in Figure 2 also show similar phenomena in terms of microstructural changes and dendritic coarsening. This finding is similar to that of Wang (2009). The grain size measurement of Fe-Ni-Cr superalloy was conducted by measuring the dendritic arm spacing (DAS). Figure 3 shows the DAS of the heat-treated samples. Both water quenched and aged samples show an increasing trend of DAS as the temperature increases. This is because the grain size is controlled by a thermally activated process through the migration of the grain boundary, where the free energy of the boundaries acts as the major driving force for grain growth (Koul \& Pickering, 1982). Thus, an increase in solution temperature provides more free energy to the boundary, which promotes grain growth and results in grain coarsening. SEM micrographs for both heat treatments show the presence of chromium carbide, $\mathrm{Cr}_{23} \mathrm{C}_{6}$ which is determined by EDX analysis. Figure 4 shows the EDX analysis of $\mathrm{Cr}_{23} \mathrm{C}_{6}$. SEM micrographs of the heat treated samples are shown in Figures 5 and 6. 

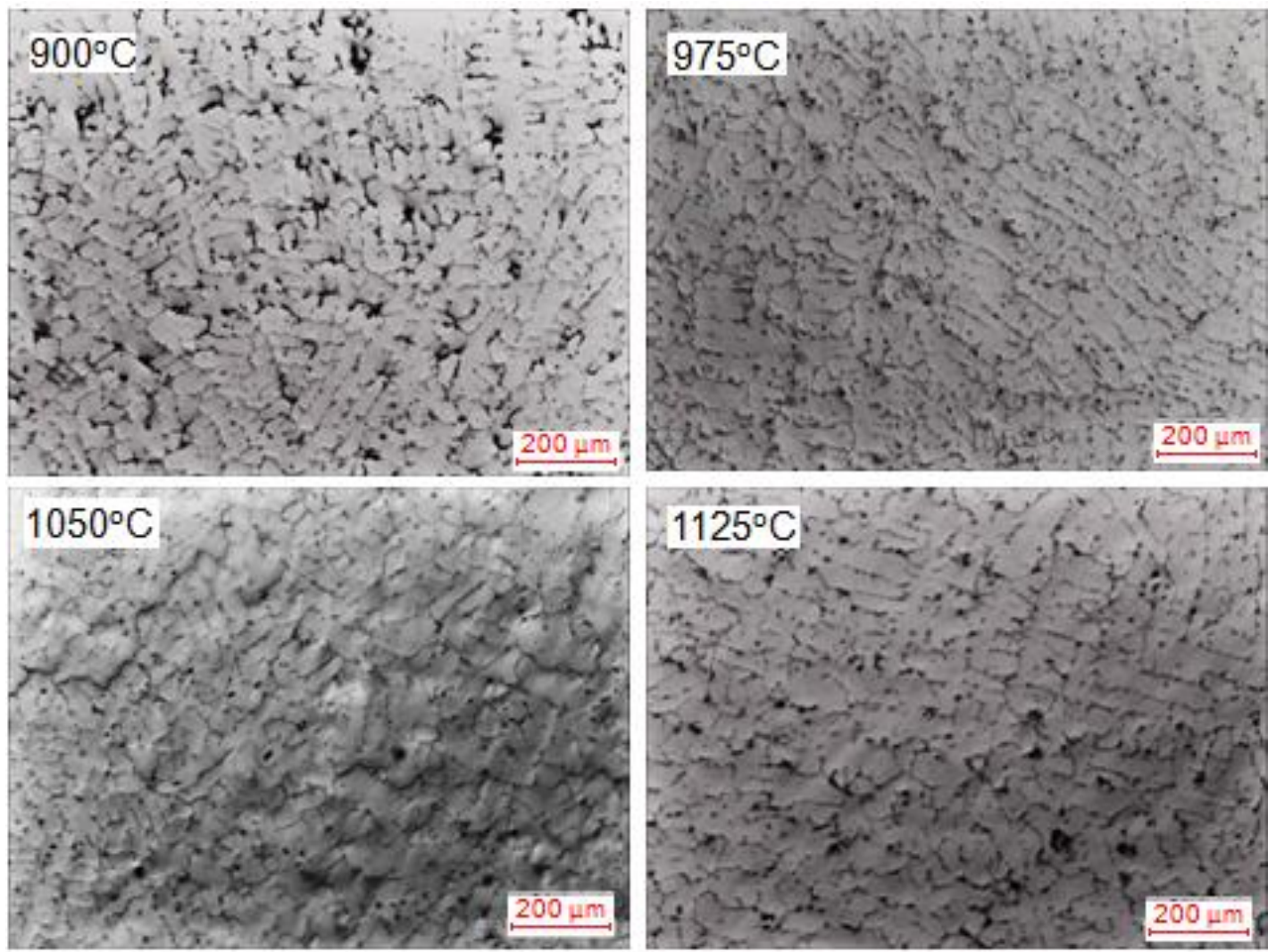

Figure 1. Optical micrographs of water quenched samples.
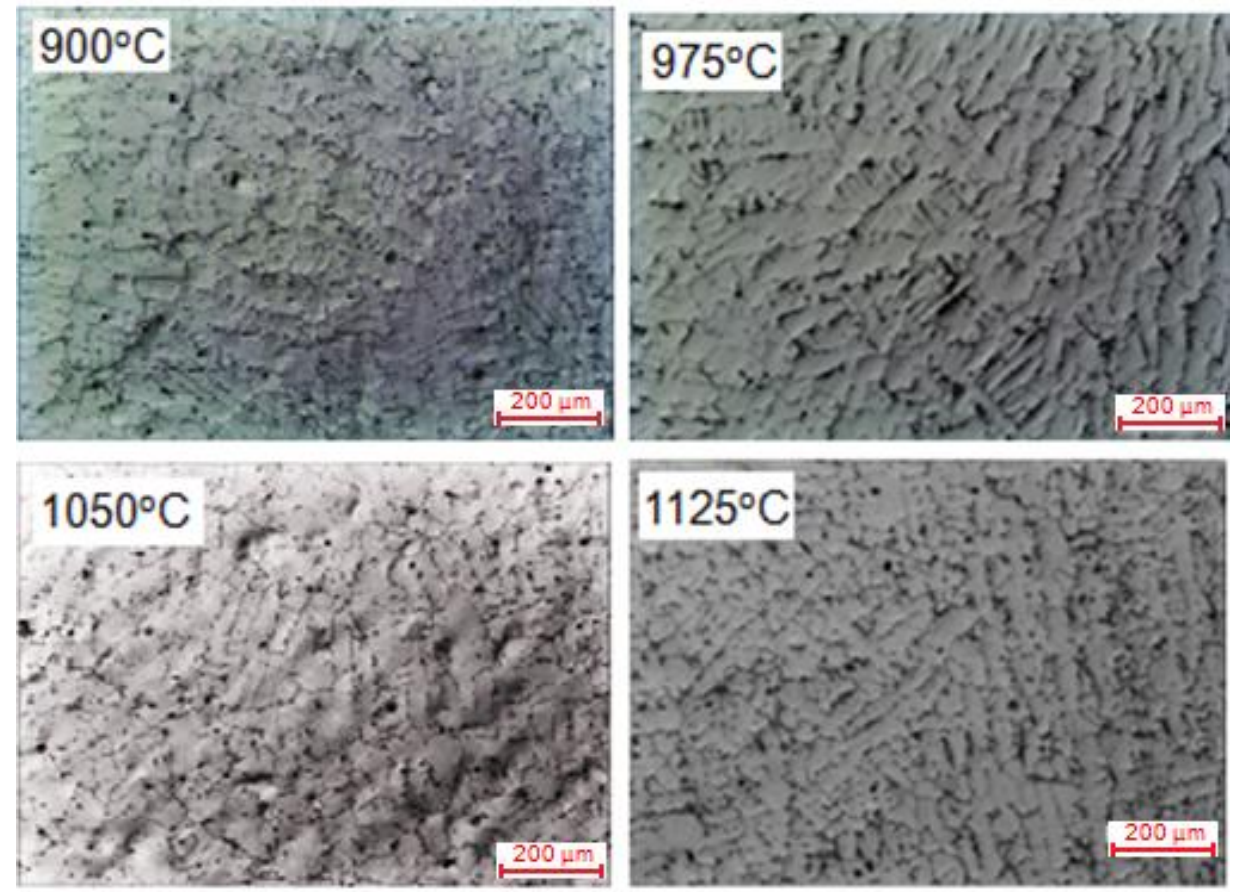

Figure 2. Optical micrographs of aged samples. 


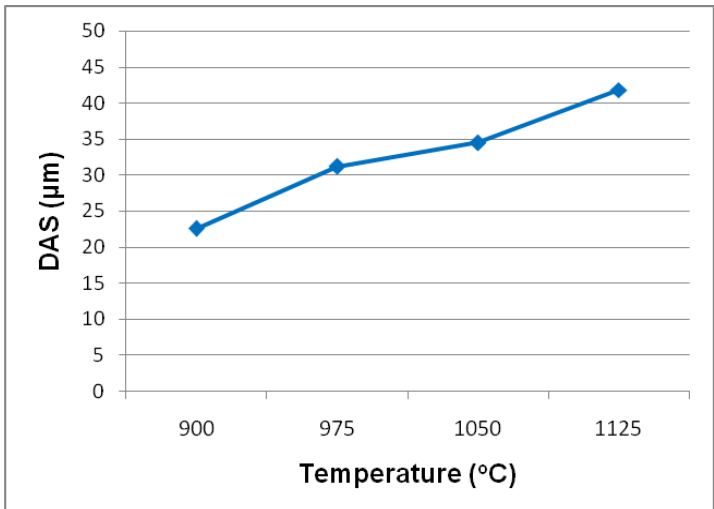

(a)

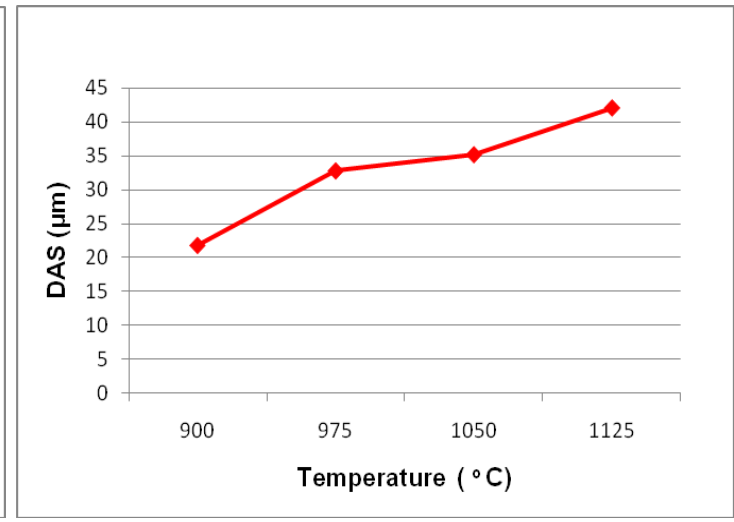

(b)

Figure 3. Effect of temperature on DAS of (a) water quenched and (b) aged samples.

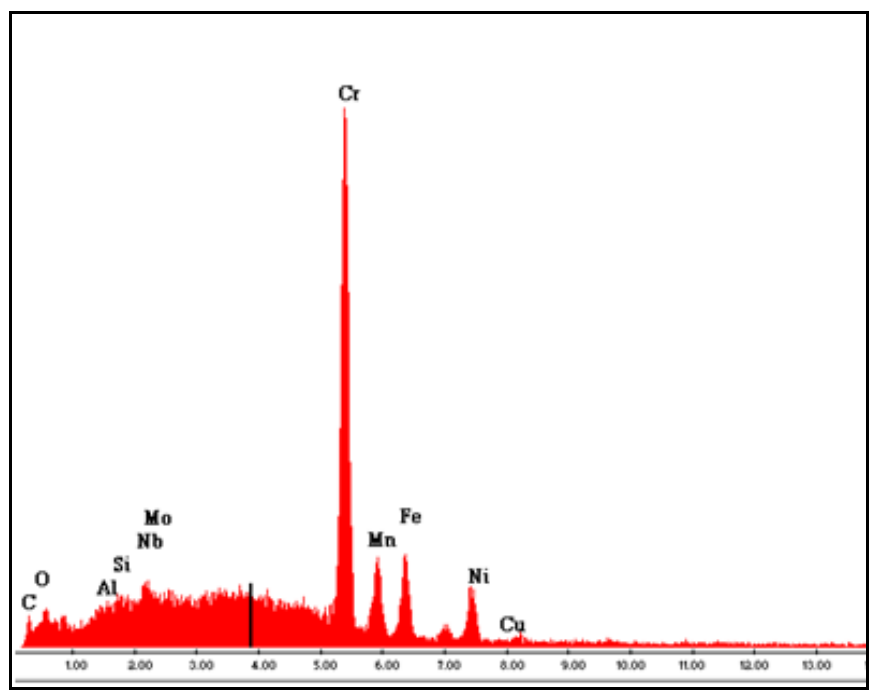

Figure 4. EDX analysis of $\mathrm{Cr}_{23} \mathrm{C}_{6}$.
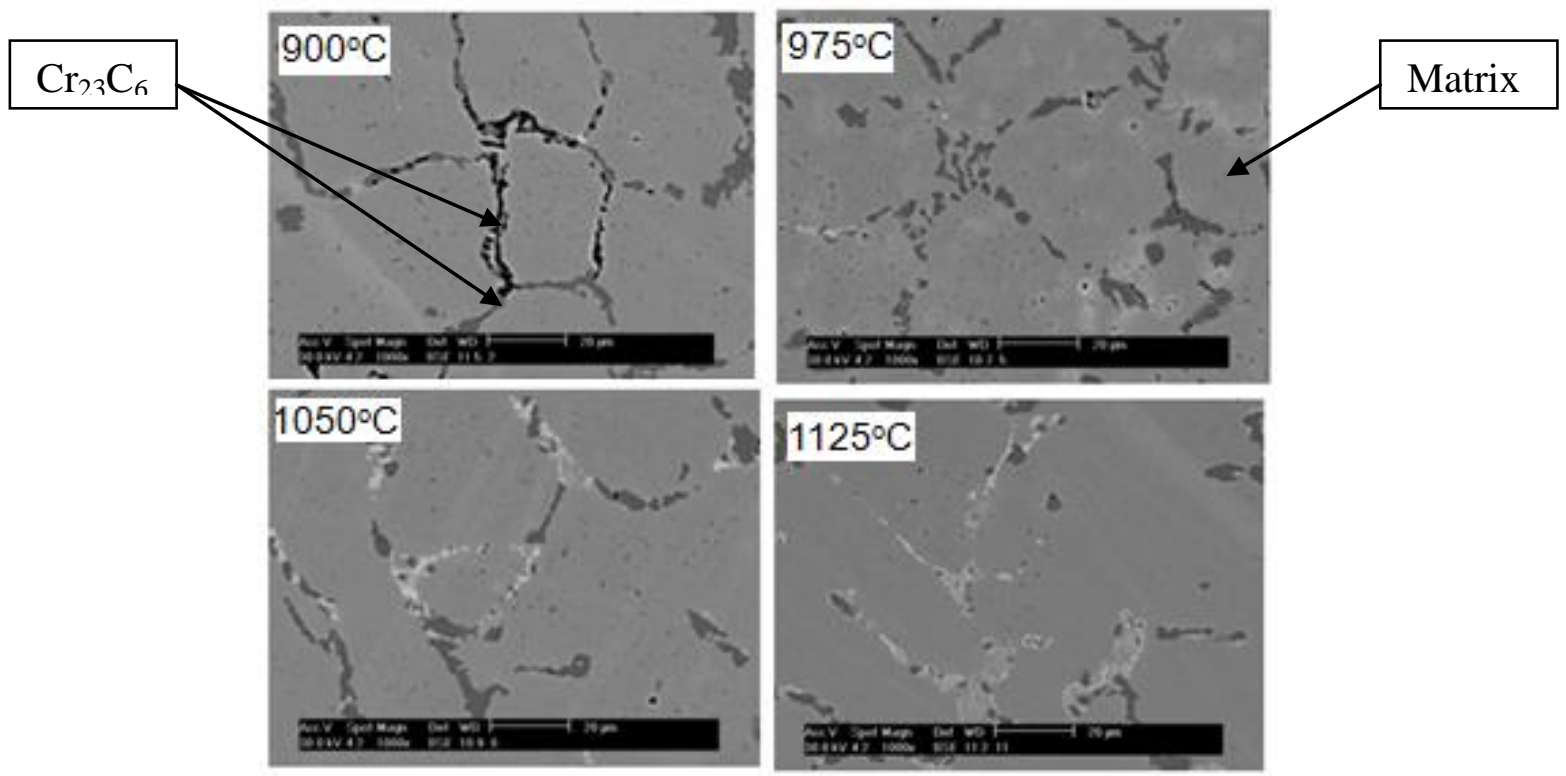

Figure 5. SEM micrographs of water quenched samples. 
As shown in Figures 5 and $6, \mathrm{Cr}_{23} \mathrm{C}_{6}$ compound was observed on the microstructure for both water quenched and aged samples. This compound was identified as the dark phase on the micrograph, which is mainly concentrated in the grain boundary area. Furthermore, area fraction analysis was conducted using an image analyzer to obtain an accurate volume fraction of the carbide phase by using Eq. (1). The amount of carbide phase observed for the water quenched samples was decreased (dissolved from the grain boundary) as the solution temperature increased. This finding is similar to that observed by Jacuinde et al. (2003). The reason for this behavior is that at higher temperatures (above $1000^{\circ} \mathrm{C}$ ), austenite can dissolve higher carbon contents, so that the amount of secondary carbides is also minor (Jacuinde et al., 2003). However, the amount of carbide observed for aged samples differed slightly, and at a temperature of $1125^{\circ} \mathrm{C}$, the quantity of carbide phase observed is higher than at $1050^{\circ} \mathrm{C}$. This might be due to precipitation of carbide during aging after being dissolved extensively at high temperature $\left(1125^{\circ} \mathrm{C}\right)$. According to Davis (1997), after the carbide is dissolved, the matrix becomes a supersaturated solid solution, thus, during aging the precipitation of this phase will occur.
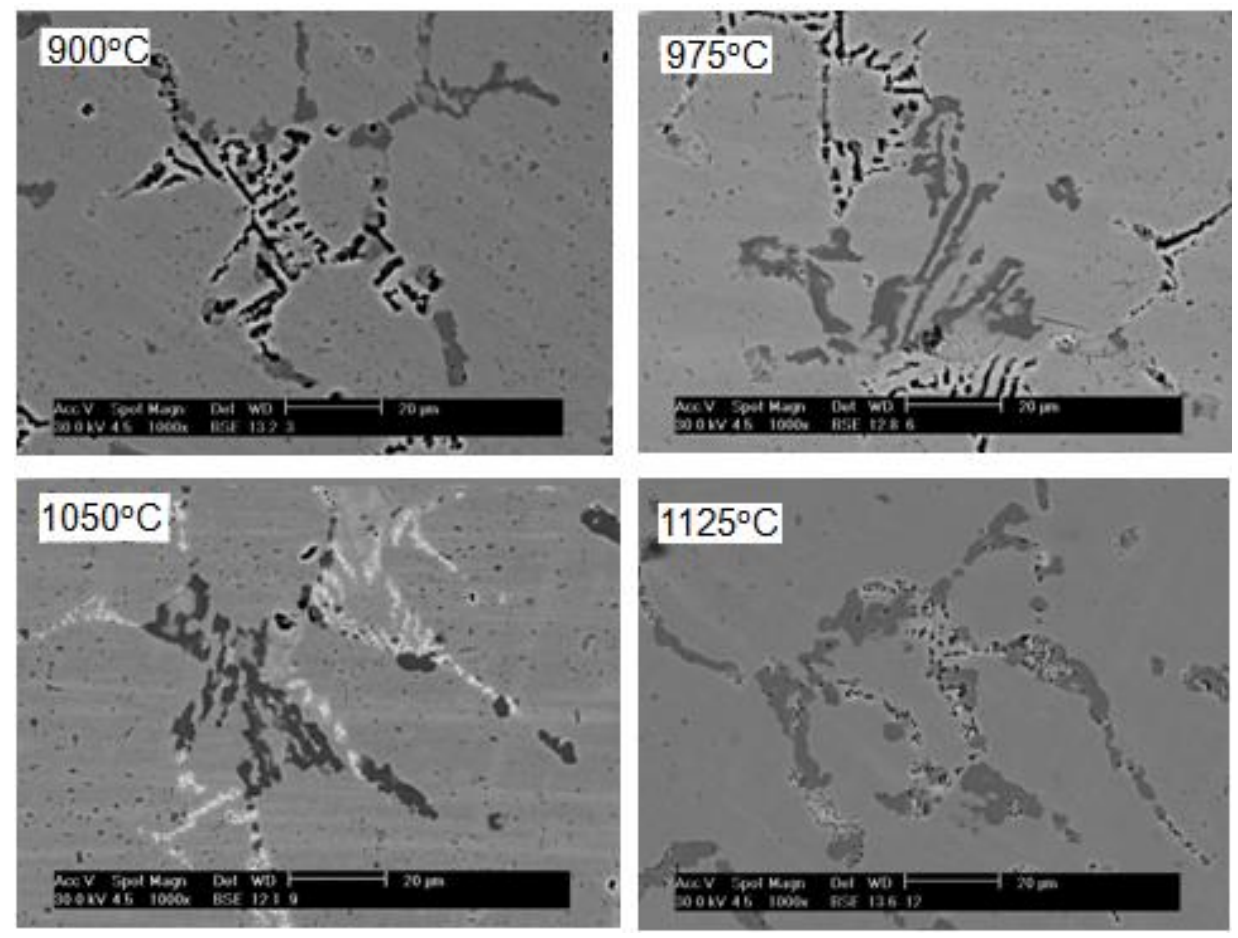

Figure 6. SEM micrographs of aged samples.

\section{Hardness}

The hardness results of the water quenched samples are shown in Figure 7. Generally, the hardness value decreased as the solution temperature increased. This finding is similar to that observed by Wang (2009). Figure 7(a) shows the effects of grain size on the hardness, where grain coarsening due to increases in temperature lowers the hardness of the material. This is because grain coarsening reduces the grain boundary strengthening effect. This finding is similar to that of Zhang et al. (2008). Meanwhile, as the grain size decreases, there is more build-up of dislocation at the grain edge. Since it requires a lot of energy to move dislocation to other grains, this dislocation will build up 
along the boundary, which increases the strength of the alloy (Zhang et al., 2008). This strengthening theory is also known as Hall-Petch strengthening. Thus, Hall-Petch strengthening is reduced as the grain size increases. On the other hand, carbide content also affects the hardness of the material. Figure 7(b) shows the effect of carbide on the hardness. The curves show that decrease in carbide content causes a decrease in the hardness of the material. This finding is similar to that observed by Jacuinde et al. (2003). The reason for this behavior is the presence of carbide precipitates, which increase the yield strength of the material by blocking the dislocation motion (Jacuinde et al., 2003), since dislocation can only move through this particle by either shearing or climbing. Thus, this interruption in dislocation motion increases the strength of the material.

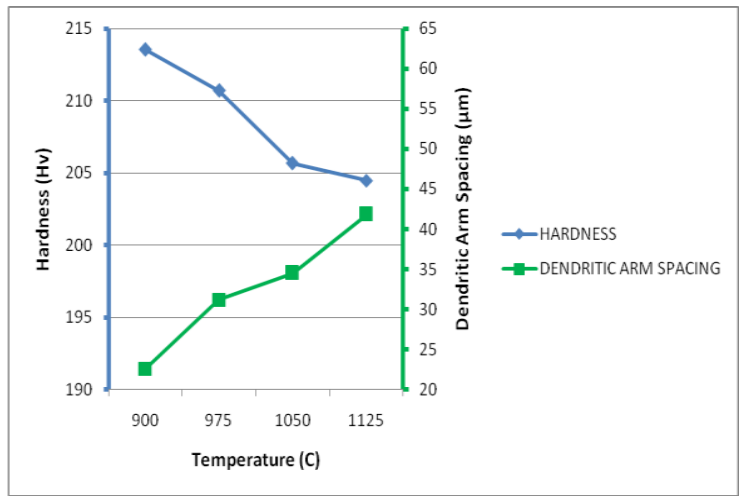

(a)

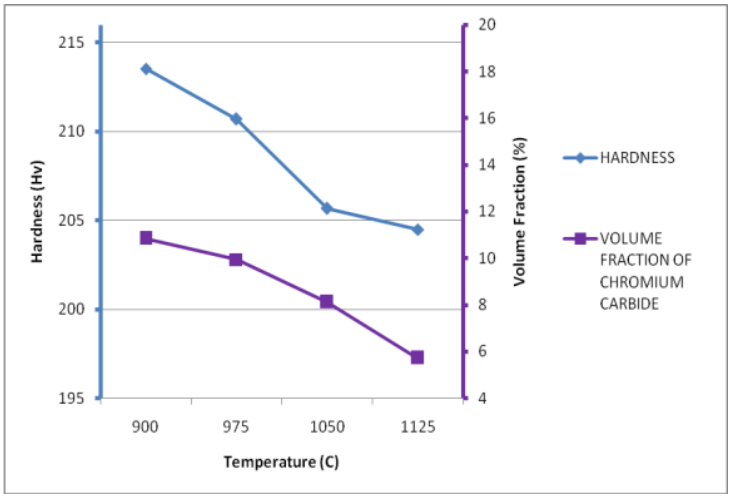

(b)

Figure 7. Effect of temperature on (a) hardness and DAS of water quenched samples;

(b) hardness and volume fraction of chromium carbide $\left(\mathrm{Cr}_{23} \mathrm{C}_{6}\right)$ of water quenched samples.

Hardness curves of the aged samples are shown in Figure 8. The curve shows a different trend from the water quenched samples. As the temperature increases from $900^{\circ} \mathrm{C}$ to $975^{\circ} \mathrm{C}$, the hardness value slightly decreases. However, as the temperature increases to $1050^{\circ} \mathrm{C}$, the hardness value increases. Then, as the temperature reaches $1125^{\circ} \mathrm{C}$, the hardness value increases markedly, reaching $220.4 \mathrm{Hv}$. The mechanical strength achieved at this temperature is the highest value obtained as compared with the other heat treatment. Figure 8(a) shows the effect of grain size on the hardness of the material. It can be seen that the grain coarsening characteristic did not reflect the unique increases in the hardness behavior, so the effect of carbide content on the hardness of aged samples was analyzed. Figure 8(b) shows the effect of carbide content on the hardness of the material. It shows that decrease in carbide content from $900^{\circ} \mathrm{C}$ to $975^{\circ} \mathrm{C}$ produces a slight decrease in hardness. However, a slight increase in hardness was observed as the carbide content continued to decrease. As the temperature increased from $1050^{\circ} \mathrm{C}$ to $1125^{\circ} \mathrm{C}$, an increase in carbide content, followed by a remarkable increase in hardness, was observed. The increase in hardness at a temperature of $1125^{\circ} \mathrm{C}$ can be related to the increase in carbide volume fraction prior to the precipitation hardening process. Even though the carbide content was slightly lower compared to the sample heated at $900^{\circ} \mathrm{C}$, the carbide precipitates at this temperature were finer. The reason for this behavior is that a large amount of carbide had been dissolved as the heating temperature reached $1125^{\circ} \mathrm{C}$, then the aging process promoted the carbide to precipitate but in a controlled atmosphere, which results in finely dispersed particles of carbide precipitates in the matrix. Stallybrass et al. (2004) explained that this form of 
carbide can give a better strengthening effect than coarser carbide. In addition, the increment in grain size from $1050^{\circ} \mathrm{C}$ to $1125^{\circ} \mathrm{C}$ was only around $4 \mu \mathrm{m}$, which did not have a significant effect in reducing its strength. However, at a temperature of $1050^{\circ} \mathrm{C}$, a decrease in carbide content still caused an increase in the hardness value. It should be noted that the sample heated at $1050^{\circ} \mathrm{C}$ also shows a certain amount of carbide dissolution. Thus, prior to aging, this sample also experienced fine carbide precipitation, which increased the strength regardless of the lower amount of carbide. This is because the carbide morphology plays an important role in terms of the strengthening effect, as stated previously by Stallybrass et al. (2004). Meanwhile, at temperatures of $900^{\circ} \mathrm{C}$ and $975^{\circ} \mathrm{C}$, carbide dissolution was hardly observed in the microstructure. Thus, the precipitation strengthening effect did not have a significant effect at these two temperatures. The hardness value tends to decrease prior to the decrease in carbide content and increase in grain size.

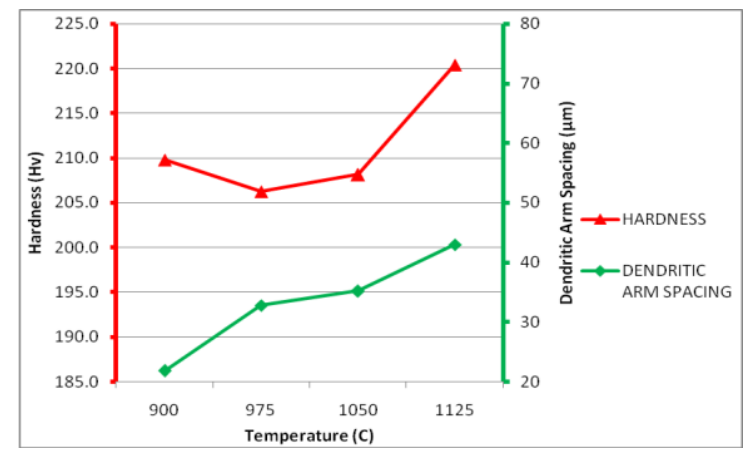

(a)

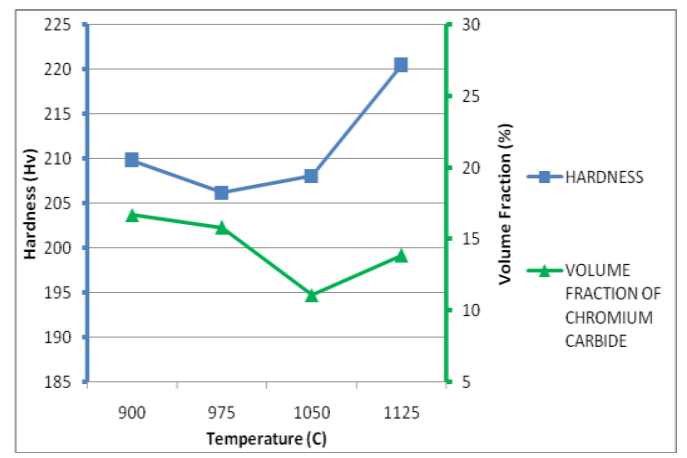

(b)

Figure 8. Effect of temperature on (a) hardness and DAS of aged samples, and (b) hardness and volume fraction of chromium carbide $\left(\mathrm{Cr}_{23} \mathrm{C}_{6}\right)$ of aged samples

\section{Effect of Aging on Quenched Samples}

Discussing the effects of aging on quenched samples after solution treatment, a critical comparison is made between water quenched and aged samples. Figure 9 shows the effect of aging on the grain size, carbide content, and hardness. As shown in Figure 9(a), there is no apparent difference in grain size after the aging process. This is because during aging, the energy supplied might not be sufficient to promote migration of the grain boundary to cause grain growth (Civjan et al., 1972). On the other hand, grain growth is also promoted by dissolution of pinning particles from the grain boundary, which is unlikely to occur during aging; instead, carbide precipitation will take place (Civjan et al., 1972). Thus, even if grain growth takes place during aging, which might be due to extremely long heating time, the amount will be so little that it will be hardly noticeable in the microstructure analysis. Figure 9(b) shows that aged samples showed a consistently higher amount of chromium carbide than water quenched samples. This shows that the aging process can markedly increase the amount of chromium carbide. However, as discussed previously, at a temperature of $1125^{\circ} \mathrm{C}$ the aged sample showed a unique increase in carbide content compared to the $1050^{\circ} \mathrm{C}$ sample. Here, the reason can be analyzed in further detail as a reflection of the amount of carbide dissolved right after the solution treatment process and before aging is conducted. As shown in the water quenched samples, at a temperature of $1125^{\circ} \mathrm{C}$, the amount of carbide was very low at about $5.7 \%$ compared to the as-received alloy which 
had about $12.6 \%$ carbide content. This means that about $6.9 \%$ of the carbide dissolved during the solution treatment at this temperature. Thus, the percentage of carbide dissolution at this temperature was higher than at other temperatures. Meanwhile, the high amount of metastable dissolved carbide in the water quenched condition had precipitated well after aging. This might be the possible cause of the increased carbide content in the aged sample at $1125^{\circ} \mathrm{C}$ solution temperature. However, it can also be seen that at temperatures of $900^{\circ} \mathrm{C}$ and $975^{\circ} \mathrm{C}$, the increase in carbide content was quite high compared to $1050^{\circ} \mathrm{C}$, even though the carbide dissolution was lower due to insufficient heat. The reason for this behavior was that the increase in carbide content was actually due to the growth of pre-existing carbide after aging, which was undesirable in terms of mechanical properties (Stallybrass et al., 2004). However, as the temperature increased to $1050^{\circ} \mathrm{C}$, more carbide started to dissolve, as shown in the SEM micrograph of the water quenched sample. According to Ridhwan et al. (2013), increase in solution temperature could lead to higher carbide dissolution from the matrix. Thus, the increase in carbide content at a temperature of $1050^{\circ} \mathrm{C}$ was mostly due to carbide precipitation rather than carbide growth, which explained the small increase in carbide content. Nevertheless, the presence of this newly precipitated carbide is in the form of fine and dispersed carbide, which is desirable in terms of mechanical properties.

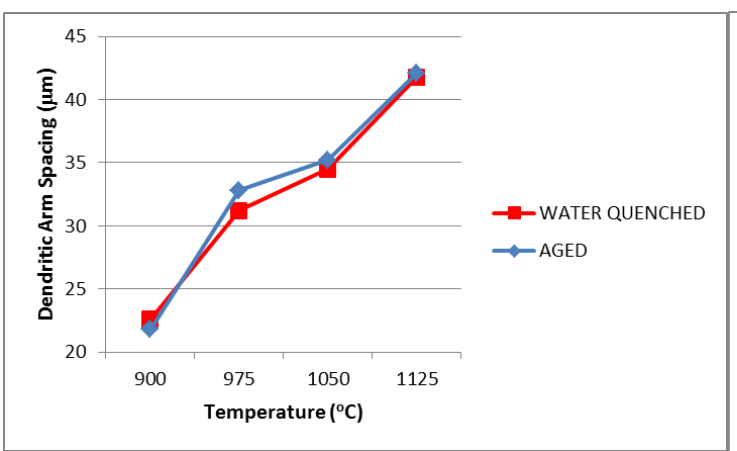

(a)

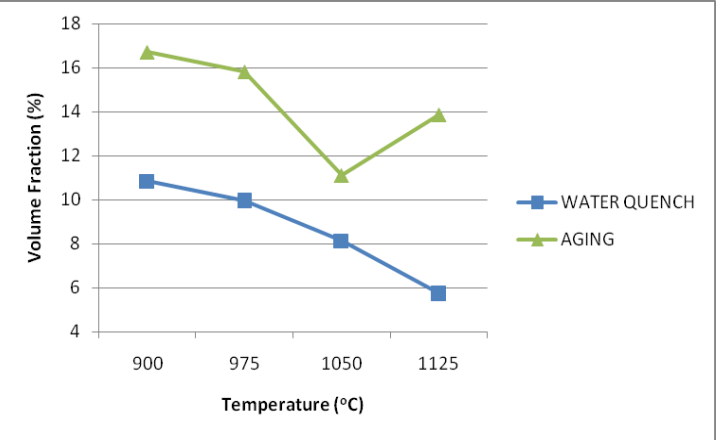

(b)

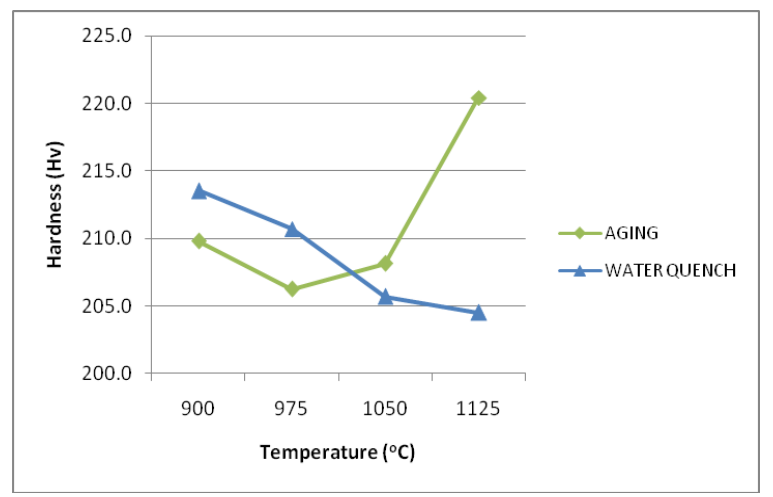

(c)

Figure 9. Effect of aging on (a) grain size, (b) carbide content, and (c) hardness of Fe$\mathrm{Ni}$-Cr superalloy

In terms of hardness, Figure 9(c) shows that, as the temperature increases from $900^{\circ} \mathrm{C}$ to $975^{\circ} \mathrm{C}$, the hardness value of water quenched samples is higher than the aged samples. However, as the temperature increases to $1050^{\circ} \mathrm{C}$ and $1125^{\circ} \mathrm{C}$, the aged samples showed higher hardness than the water quenched samples which are in the solution heat-treated state. At temperatures below $1050^{\circ} \mathrm{C}$, the higher hardness of the 
water quenched samples can be attributed to the finer precipitate of pre-existing carbide compared to the aged samples, which have a coarser carbide morphology. Meanwhile, at temperatures of $1050^{\circ} \mathrm{C}$ and $1125^{\circ} \mathrm{C}$, the lower hardness value of the water quenched samples is due to high carbide dissolution which causes extremely low content of carbide precipitate. At the same time, the increase in hardness in the aged samples is due to the presence of finely dispersed particles of carbide precipitate which further increase the hardness of the samples.

\section{XRD Analysis}

On the other hand, XRD analyses were also conducted to identify the phase transformation after aging. Figure 10 shows the XRD patterns of aged samples and water quenched samples. No new peak is observed due to the aging treatment. At the same time, the pre-existing peak can still be observed after the aging process. This shows that no new phase was being formed and no pre-existing phase was transformed prior to the aging treatment. This is because the as-received material had shown austenitic structure before the aging process, which has high stability and is not likely to transform into another phase under the aging treatment. This behavior is similar to that found by Gheno et al. (2011).
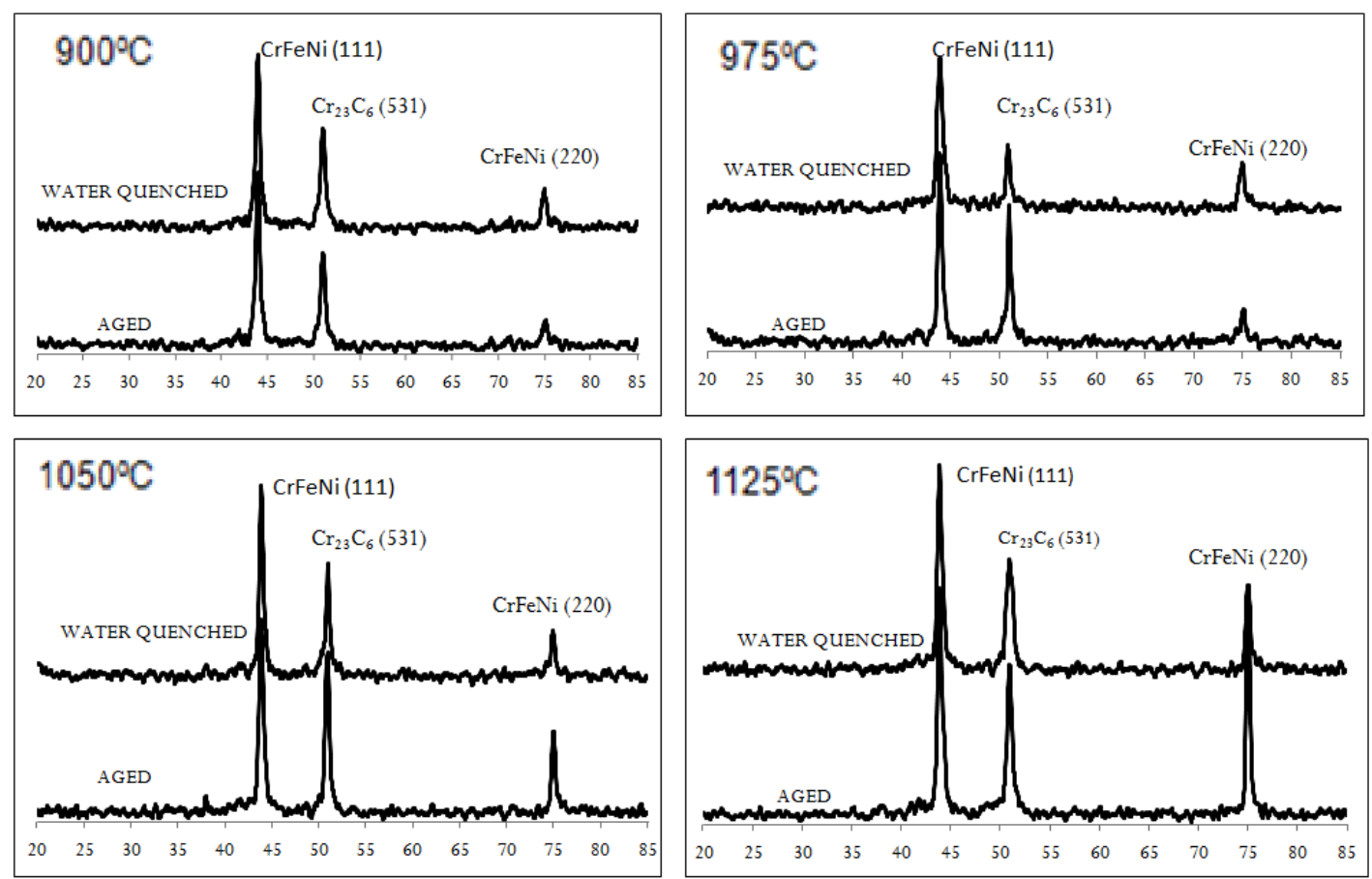

Figure 10. XRD pattern of water quenched and aged samples.

\section{CONCLUSIONS}

The effects of aging treatment on the microstructure and hardness of $\mathrm{Fe}-\mathrm{Ni}-\mathrm{Cr}$ superalloy have been investigated. Microstructure investigation and hardness tests have been conducted as well. Analysis of the results leads to a few major conclusions. In terms of solution treatment, increase in temperature leads to increase in grain size but reduces the chromium carbide, $\mathrm{Cr}_{23} \mathrm{C}_{6}$ content and the hardness value. In addition, for 
non-aged samples, grain coarsening behavior reduces the hardness value due to its low grain boundary strengthening effect. Higher amounts of fine chromium carbide in microstructure increase the hardness value due to the precipitation strengthening effect, while lower amounts of fine chromium carbide reduce the hardness value. Aging treatment increases the amount of chromium carbide, which further increases the hardness value of the alloy by precipitation strengthening. The highest average hardness value of $220.4 \mathrm{Hv}$ and tensile strength $743.1 \mathrm{MPa}$ was recorded on the sample solution treated at $1125^{\circ} \mathrm{C}$ for 2 hours (water quenched) and aged at $720^{\circ} \mathrm{C}$ (air cooled) then $650^{\circ} \mathrm{C}$ (air cooled) for 4 hours and 12 hours respectively. The XRD pattern shows that neither phase formation nor phase transformation was observed during all the series of heat treatments conducted.

\section{ACKNOWLEDGMENT}

The author wishes to thank Universiti Teknikal Malaysia Melaka (UTeM) for providing the opportunity and financial support to conduct this research activity. The author would also like to acknowledge the support from Nuclear Malaysia for providing research material, as well as the Malaysian Ministry of Higher Education (MOHE) and Universiti Teknologi Malaysia for providing the financial support and facilities under the Research University Grant Vote No. 04J95.

\section{REFERENCES}

Al Qura'n, F. (2009). Effect of heat treatment on the microstructure and hardness of chromium-nickel steel. Journal of Contemporary Engineering Sciences, 2(8), 355-359.

ASM Handbook Vol. 4. (1991). Heat treating of superalloy.

ASM Specialty Handbook (1997). Heat-resistant materials. J.R. Davis (Ed.).

Cai, D. Y., Yao, M., Nie, P. L., \& Liu, W. C. (2003). Influence of solution treatment temperature on mechanical properties of a $\mathrm{Fe}-\mathrm{Ni}-\mathrm{Cr}$ alloy. Journal of Materials Letters, 57, 3805-3809.

Civjan, S., Huget, E. F., \& Godfrey, G. D. (1972). Effects of heat treatment on mechanical properties of two nickel-chromium-based casting alloys. Journal of Dental Research, 51, 1537.

Das, S., Ghosh, A., Chatterjee, S., \& Ramachandra Rao, P. (2003). The effect of cooling rate on structure and properties of a HSLA forging. Scripta Materialia, 48, 5157.

Gheisaria, Kh., Ohb, J. T., \& Javadpourc, S. (2011). The effect of heat treatment on the structure and magnetic properties of mechanically alloyed $\mathrm{Fe}-45 \% \mathrm{Ni}$ nanostructured powders. Journal of Alloys and Compounds, 509, 1020-1024.

Gheno, T., Monceau, D., Zhang, J., \& Young, D. J. (2011). Carburisation of ferritic FeCr alloys by low carbon activity gases. Journal of Corrosion Science, 53, 27672777.

Hasemann, G., Schneibel, J. H., \& George, E. P. (2012). Dependence of the yield stress of $\mathrm{Fe} 3 \mathrm{Al}$ on heat treatment. Intermetallics, 21, 56-61.

Jabbari Behnama, M. M., Davamia, P., \& Varahrama, N. (2010). Effect of cooling rate on microstructure and mechanical properties of gray cast iron. Journal of Materials Science and Engineering A, 528, 583-588. 
Jacuinde, A. B., Arias, L., \& Hernández, B. (2003). Kinetics of secondary carbides precipitation in a high-chromium white iron. Journal of Materials Engineering and Performance, 12(4), 371-382.

Jie, Z., Qing, W., Yingmin, W., Lishi, W., \& Chuang, D. (2010). Effect of heat treatment on the highly corrosion-resistant $\mathrm{Cu}_{70} \mathrm{Ni}_{27} .7 \mathrm{Fe}_{2.3}$ alloy. Journal of Alloys and Compounds, 505, 505-509.

Koul, A. K. \& Pickering, F. B. (1982). Grain coarsening in Fe-Ni-Cr alloys and the influence of second phase particles. Acta Metallica, 30, 1303-1308.

Lu, Y. H., Xing, Q., \& Zhang, H. (1995). Effect of heat treatment temperature on tensile properties of a Fe-28Al-5Cr-0.3B-0.003Mg alloy. Scripta Metallurgica et Materiala, 33(4), 609-613.

Moniruzzaman, M., Rakib, M. M., \& Matin, F. T. (2012). Cr-Ni alloy electrodeposition and its comparison with conventional pure $\mathrm{Cr}$ coating technique. International Journal of Automotive and Mechanical Engineering, 6, 693-701.

Qamar, S. Z. (2009). Effect of heat treatment on mechanical properties of H11 tool steel. Journal of Achievements in Materials and Manufacturing Engineering, 35(2), 115-120.

Ridhwan, J., Hamzah, E., Effendy, H., Selamat, M. Z., \& Zulfattah, Z. (2013). Effect of cooling rate on the microstructures and hardness of $\mathrm{Fe}-\mathrm{Ni}-\mathrm{Cr}$ superalloy. Journal of Mechanical Engineering and Technology, 5(1), 45-57.

Salleh, S. H., Omar, M. Z., Syarif, J., \& Abdullah, S. (2009). Carbide formation during precipitation hardening of SS440C steel. European Journal of Scientific Research, 34(1), 83-91.

Sims, C., Stoloff, N., \& Hagel, W. (1987). Superalloys II: High temperature materials for aerospace and industrial power. John Wiley.

Stallybrass, C. \& Sauthoff, G. (2004). Ferritic Fe-Al-Ni-Cr alloys with coherent precipitates for high-temperature applications. Journal of Materials Science and Engineering A, 387-389, 985-990.

Wang, X. F. (2009). Effects of high temperature and cryogenic treatment on the microstructure and abrasion resistance of a high chromium cast iron. Journal of Materials Processing Technology, 209, 3236-3240.

Zhang, L. Y, Jiang, Y. H, Ma, Z., Shan, S. F, Jia, Y. Z., Fan, C. Z., \& Wang, W. K. (2008). Effect of cooling rate on solidified microstructure and mechanical properties of aluminium-A356 alloy. Journal of Materials Processing Technology, 207, 107-111. 